\title{
Concept Development of a New Lumbar Intervertebral Disk Implant
}

\author{
Cristian-Vasile Doicin ${ }^{1}$, Mihaela-Elena Ulmeanu ${ }^{1,}{ }^{*}$, Alexa-Sorina Frîncu ${ }^{1}$, and Vlad- \\ Cristian Enache ${ }^{1}$ \\ ${ }^{1}$ University POLITEHNICA of Bucharest, Splaiul Independenței, No. 313, Sector 6, Bucharest, \\ Romania
}

\begin{abstract}
Worldwide spinal cord injury incidence is rising, due to spikes in traffic incidences, violence and an increase in ageing population, prone to injuries. To satisfy an expanding market, a wide variety of spinal implantable devices are available. The current study develops a new concept for a lumbar intervertebral disk implant which addresses the disadvantages of current commercialised devices. The proposed intervertebral disk implant concept limits the anatomical movements of the trunk, replicating the functions of a natural intervertebral disk. Three concept variations were designed and evaluated using FEA simulations for three main operating hypotheses: Compression of vertebrae in normal upright position; Lifting weights at a correct and at an incorrect angle; Shock in the lumbar region. Von Misses stress, URES: Resultant Displacement and ESTRN: Equivalent Strain studies were used to evaluate the capability of the intervertebral disk implant concept to withstand the design load. Concept 3 failed URES and ESTRN simulations for the hypotheses which involved lifting weights and delivering a shock in the lumbar region. Simulation revealed optimum results for Concept 1 , which was selected for further research.
\end{abstract}

\section{Introduction}

Worldwide, according to World Health Organization (WHO), there are between 250 and 500 thousands of people suffering from spinal cord injuries (SCI) and up to $90 \%$ of these injuries are traumatic, thus they require the implication of a surgical procedure. The main causes for the traumatic SCI are road traffic crashes, falls or violence. WHO also states that spinal cord injuries "carry substantial individual and societal costs" [1]. Furthermore, a study of the literature that discusses the incidence and prevalence of SCI worldwide, presents that the main causes are car crashes and falling in elderly population [2]. According to the study "Global prevalence and incidence of traumatic spinal cord injury" [3] the United States of America has the highest (906 per million) prevalence of SCI, the lowest values being registered in the Rhone-Alpes region, France ( 250 per million) and Helsinki, Finland (280 per million). Even if the epidemiology of SCI seems to rise worldwide, as of 2007, in Romania an average of 23 cases per million were registered, and

\footnotetext{
*Corresponding author: mihaela.ulmeanu@upb.ro
} 
179,312 cases per year [3]. According to the report "Spinal Implants and Surgical Devices Market (...) Global Forecast to 2021", spinal implants and spinal surgeries devices market will reach USD 17.27 Billion by 2021 [4]. The first place for both prevalence of SCI and market share is taken by North America, followed closely by Europe. Considering the rising number of spinal cord injuries, traumatic or non-traumatic, the need to conduct research and development for new concepts of spinal implants is necessary, with focus on decreasing surgery costs, speeding up the healing process, along with ensuring a better patient compliance and an increase in the quality of life.

A variety of both standardised and bespoke spinal implants are available on the market, each catering specific patient needs and performing targeted functions $[5,6]$. In order to align the spine in the correct position, the mainly-used spinal implants at the moment, without the requirement of special customized features, are: rods, hooks, screws, plates and cages $[6,7]$. All of these show limitations in terms of patient compliance and anatomy adaptability $[8,9,10]$. Also, several types of complex spinal implantable devices have been developed so far, which include: general surgery systems, access and minimally invasive access systems, anterior column plating, interbody and vertebral body replacement systems, spine augmentation systems $[4,6,11]$. Current inter vertebral disk (IVD) bearings tend to be axially rigid and are not designed to resist bending or rotational moments, allowing motion to occur in excess of that permitted by the natural disc [9, 12]. Ball and socket bearings do not completely replicate the functions of the natural IVD, as they tend to increase the hypermobility of the joint, which can lead to several types of complications [7, $13,14]$. Current spinal surgery procedures which require implantation of a medical device, show a variety of complications, amongst the most important are $[3,5,7,13,14]$ : Regarding spinal fusions, a non-union which undergoes a second surgery; Hardware fractures, like screws getting misplaced; Implant migration; Transitional Syndrome; Paralysis; Death. Manufacturing methods and materials used to obtain such implant systems are available in a wide variety, each with proven advantages $[5,6,15,16]$. The unrivalled geometric freedom of design provided by AM technologies has contributed significantly to its adoption rate in the medical industry, especially in implantology $[6,17$, 18]. Manufactured by metal sintering, the most common used AM spinal implants are fixed, with internal porous structure for light weight and osseointegration properties $[8,15$, $18,19,20]$. In this regard, the current research paper proposes the development of a new intervertebral disk implant concept which brings together the geometry freedom of additive manufacturing with the benefits of standardised medical products.

The main innovations relative to the current state of knowledge are: 1. Improve osseointegration of the intervertebral disk implant through design and manufacture of gripping elements; 2. Diminish the strains in the joints by designing specific gliding surfaces; 3. Limitation of movement within the admissible anatomical and biomechanical limits through innovative geometrical features of the implant joint and elastic core; 4. Modular construction of interlocking joints, which aims at streamlining a possible scale manufacturing of the implant.

\section{Concept development of a new lumbar intervertebral disk implant}

\subsection{Concept development and CAD modelling}

Product design and development is a complex process, comprised of numerous stages, as follows: Reason statement; Product (implant) planning and mission statement; Customers' 
needs portfolio identification; Opportunities, similar products and customers definition; Restrictions identification to developing the implant prototype; Decision matrix compilation for implant concept selection; Mission statement for selected concept development; Identification of customers' needs for the lumbar implant; Setting the specifications of the lumbar implant; Generating implant concepts; Clarifying the problem and defining the general function of the implant; Collection of conceptual solutions for the development of main functions (External research); Generating new conceptual solutions; Concept screening; Concept scoring, Lumbar implant concept selection. All the above mentioned stages were deployed [21] and three variations of the chosen lumbar intervertebral disk implant concept were modelled using SolidWorks Premium 2016 Design Software (Figure 1).
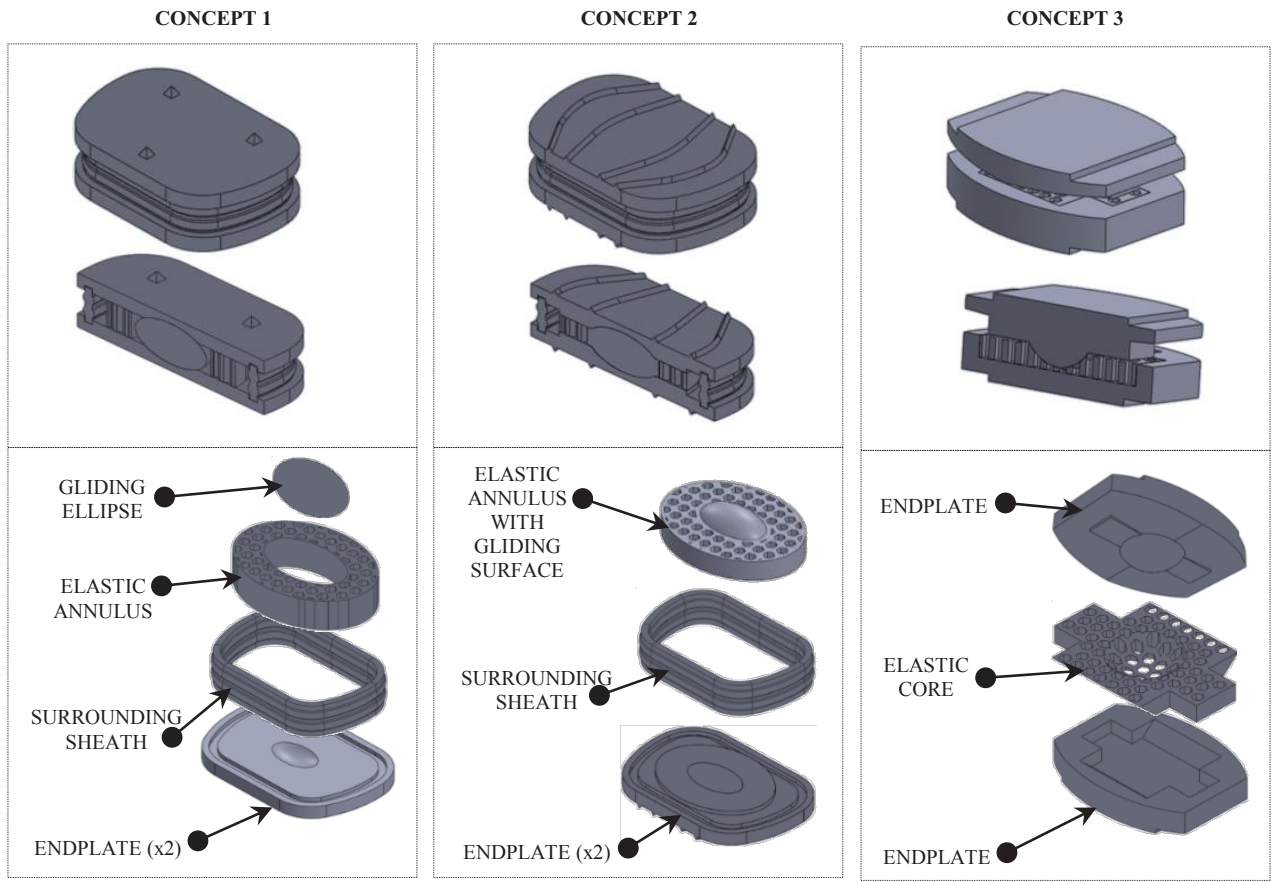

Fig. 1. Main components of the lumbar intervertebral disk implant concept variations.

The IVD implant consists of a nucleus and a surrounding annulus ring. The annulus is assumed to provide shock absorbance. These elements are defined by the study of literature and the former analysis of different aspects. Mean disc height in the lumbar segment was defined between 10 to $12 \mathrm{~mm}$, length varies from 20 to $40 \mathrm{~mm}$ and width from 20 to $30 \mathrm{~mm}$ $[9,10,12-14]$. The three variations of the chosen concept and their main components are presented in Figure 1. The endplates and gliding ellipse of the final lumbar intervertebral disk implant will be manufactured from a titanium alloy (Ti-6Al-4V) and the elastic annulus and surrounding sheath from polyurethane (11671). The mechanical properties of both materials were considered those given by SolidWorks Premium 2016 Design Software build in material library.

\subsection{Simulation Development}

Simulation was undertaken using SolidWorks software package defining three types of studies for each of the three hypotheses, as follows: Von Misses stress; URES: Resultant 
Displacement and ESTRN: Equivalent Strain. For all simulations the bottom endplate was considered fixed and a global contact set was defined for all three CAD concepts. Bonded contact sets were defined for components of the concept variations presented in figure 1 . All initial charts were set to show an automatic deformed shape without a superimposed model. Number formats were set to scientific and the legend had an automatically defined minimum and maximum values. Meshing was undertaken using the characteristics given in Table 1. No errors were found when meshing the assembly.

Table 1. Mesh characteristics of the lumbar intervertebral disk implant concept variations.

\begin{tabular}{l|c|c|c}
\hline \multicolumn{1}{c|}{ Mesh characteristics } & Concept 1 & Concept 2 & Concept 3 \\
\hline Mesh type & Solid Mesh & Solid Mesh & Solid Mesh \\
\hline Mesher Used: & Standard mesh & Sandard mesh & Sandard mesh \\
\hline Jacobian points [Points] & 4 & 4 & 4 \\
\hline Element Size [mm] & 2.04721 & 2.08788 & 1.96323 \\
\hline Tolerance [mm] & 0.102 & 0.104 & 0.098 \\
\hline Mesh Quality & High & High & High \\
\hline Total Nodes & 36679 & 281368 & 27697 \\
\hline Total Elements & 120677 & 188094 & 16840 \\
\hline Maximum Aspect Ratio & 72.508 & 167.74 & 15.952 \\
\hline \% of elements with Aspect Ratio $<3$ & 70.1 & 98.1 & 90.4 \\
\hline \% of elements with Aspect Ratio $>10$ & 1.64 & 0.1 & 0.0297 \\
\hline \% of distorted elements (Jacobian) & 0 & 0 & 0 \\
\hline Time to complete mesh [s]: & 35 & 22 & 11 \\
\hline
\end{tabular}

Load distributions were defined taking into consideration several hypotheses. Three working hypotheses were taken into consideration and analysed in order to understand how the forces act upon the intervertebral disk implant in operation and how well it responds to deformations and stresses. The three hypotheses are: 1 . Normal position - compression; 2. Lifting weights: a) correctly, b) wrong (at an incorrect angle); 3. Shock in the lumbar region. The design loads for each hypothesis was set according to literature and own calculations.

\section{Hypothesis 1 - Compression of vertebrae in normal up-right position}

In the upright standing position the compressive force which acts on the intervertebral disk implant is the weight (W) applied in the centre of gravity of the disc of the upper body $[9,10]$. The weight is calculated using relation (1).

$$
W=m \cdot g \quad[N]
$$

Where, $m$ is the upper body mass, and was averaged according to $[9,10]$ at $38 \mathrm{~kg}$ $\mathrm{g}$ - gravitational acceleration, and was considered $10 \mathrm{~m} / \mathrm{s}^{2}$

Thus, using relation (1) the compressive force which acts on the intervertebral disk implant in a normal standing position was set at $380 \mathrm{~N}$.

Hypothesis 2 - Lifting weights at a correct and at an incorrect angle

Implant displacement is commonly encountered when lifting weights [9] and can lead to serious surrounding tissue damage, pain, hernia and even paralysis [13, 14]. These complications can be avoided if a correct position of the upper body is maintained during lifting. An angle of $80^{\circ}$ of the upper body is considered to ensure safe conditions when lifting weights $[9,10]$. By changing the position when lifting to an angle of $65^{\circ}$ significantly higher forces will be registered $[9,10]$, usually leading to implant damage and spinal injury. The forces which act on an intervertebral disk wile lifting are presented in Figure 2. 


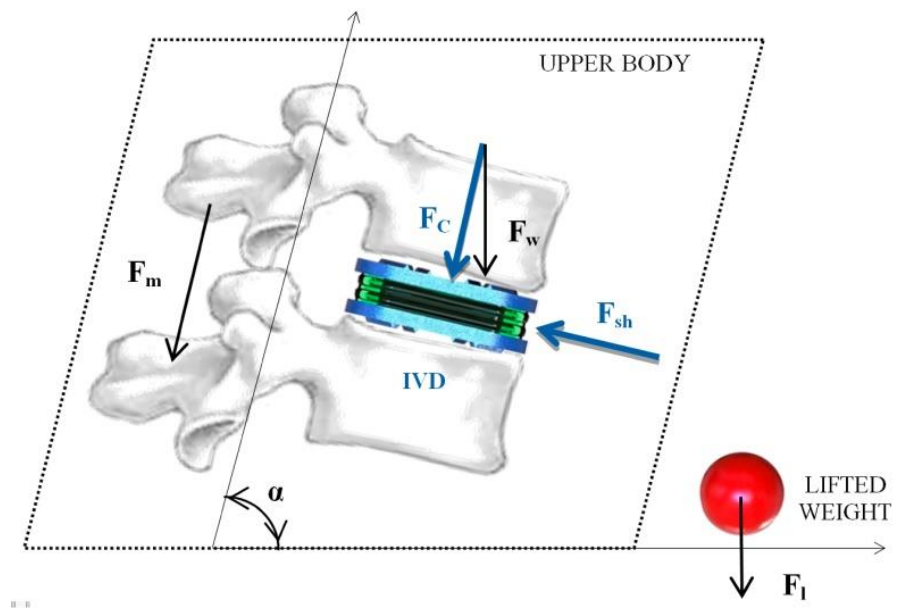

Fig. 2. Loads distribution on an intervertebral disk while lifting weights.

Two main forces are identified within the load distribution for a loading action, namely the compressive force $\left(\mathrm{F}_{\mathrm{c}}\right)$ and the shear force $\left(\mathrm{F}_{\mathrm{sh}}\right)$. The compressive force which acts on the intervertebral disk implant will be calculated for both cases of hypothesis 2 using relation (2). The shear force was computed using formula (3).

$$
F_{c}=F_{m}+F_{w x}+F_{l x}[N]
$$

Where, $\mathrm{F}_{\mathrm{m}}$ is the force applied by the muscles to maintain position $[N]$

$\mathrm{F}_{\mathrm{w}}$ - the weight of the upper body $[N]$

$\mathrm{F}_{1}$ - the weight of the lifted object $[N]$

$\mathrm{F}_{\mathrm{c}}$ - compressive force exercised on the disc $[N]$

$\mathrm{F}_{\mathrm{sh}}-$ shear force $[N]$

$\alpha$ - angle of the upper body $\left[{ }^{0}\right]$

$$
F_{s h}=F_{w y}+F_{l y}[N]
$$

Thus, in case of hypothesis $2 a$ the loads distribution was calculated for a lifting angle of $80^{\circ}$ using the following input values: $F_{m}=3020 \mathrm{~N}[9] ; F_{w}=380 \mathrm{~N} ; F_{1}=300 \mathrm{~N} ; \alpha=80^{\circ}$. The mass of the lifted load was considered to be $30 \mathrm{~kg}$.

$$
\begin{gathered}
F_{c / 2 a}=3020+380 \cdot \sin \left(80^{\circ}\right)+300 \cdot \sin \left(80^{\circ}\right) \Rightarrow F_{c / 2 a}=3690 \mathrm{~N} \\
F_{s h / 2 a}=380 \cdot \cos \left(80^{\circ}\right)+300 \cdot \cos \left(80^{\circ}\right) \Rightarrow F_{s h / 2 a}=118 \mathrm{~N}
\end{gathered}
$$

For hypothesis $2 b$ the loads distribution was calculated for a lifting angle of $65^{\circ}$ using all the other input values as for hypothesis $2 \mathrm{a}$.

$$
\begin{gathered}
F_{c / 2 b}=3020+380 \cdot \sin \left(65^{\circ}\right)+300 \cdot \sin \left(65^{\circ}\right) \Rightarrow F_{c / 2 b}=4866 \mathrm{~N} \\
F_{s h / 2 b}=380 \cdot \cos \left(65^{\circ}\right)+300 \cdot \cos \left(65^{\circ}\right) \Rightarrow F_{s h / 2 b}=287 \mathrm{~N}
\end{gathered}
$$

Hypothesis 3 - Shock in the lumbar region

An impact force on $5000 \mathrm{~N}$ was considered for simulation of the falling scenario, as this is the compression tolerance of the lumbar spine given by literature [22]. 


\subsection{Rapid prototyping}

Rapid prototyping was done for concept validation and component fitting. In preparation for $3 \mathrm{D}$ printing, an $* \mathrm{STL}$ file is compiled for each implant component from the CAD models. Based on the *.STL files the 3D printer will manufacture the final part. Involving only general component fitting and concept validation a Fused Deposition Model (FDM) technology was chosen to $3 \mathrm{D}$ print the lumbar intervertebral disk implant prototype. Prototype function, medium accuracy, high printing speed and low material cost lead to the selection of this additive manufacturing (AM) technology. 3D printing was undertaken using a 3D Kreator equipment with PLA filament for all print jobs. The filament diameter is $1.75 \mathrm{~mm}$ and the material density $1.2 \mathrm{~g} / \mathrm{cm}^{3}$. A $1 \mathrm{~kg}$ spool of PLA filament was purchased at a price of $30 €$. Prototype 3D printing was done following the main FDM manufacturing stages, which are summarized in Table 2.

Table 2. Specific FDM manufacturing stages using Simplify 3D software and 3D Kreator printer.

\begin{tabular}{l|l}
\multicolumn{1}{c|}{ FDM Stage } & \multicolumn{1}{c}{ Intermediary stages } \\
\hline S1. Print job preparation & IS 1.1. PLA material profile loading \\
& IS 1.2. Part orientation, positioning and scaling on the build \\
& platform \\
& IS 1.3 . Support structure generation \\
& IS 1.4 . Process parameters setting for implant shape and \\
& functionality \\
\hline F2. 3D printing using & IS 2.1. Equipment preparation: heat print platform at $60^{\circ} \mathrm{C}$, heat \\
FDM technology & print head at $215^{\circ} \mathrm{C}$, print head positioning at start point \\
& IS 2.2. FDM 3D printing \\
& IS 2.3. Heating of the printing platform at $80^{\circ} \mathrm{C}$ for easy part \\
& removal \\
\hline S3. Post-processing & IS 3.1. Part removal \\
& IS 3.2. Support structure deburring \\
& IS 3.3. Part cleaning \\
\hline
\end{tabular}

Process parameters were determined using the Simplify 3D software tool, which offers a wide variety of customisable printing features. Print preparation started with selection of the appropriate material printing profile, which in this case is standard PLA. By doing so, the 3D printer automatically loads process parameter values for working with standard PLA material. Using these predefined parameters does not guarantee a successful print job. Thus, using their experience, the authors set the 3D printing process parameters in correspondence with the size, shape geometry and functional surfaces of the lumbar intervertebral disk implant prototype. As there are over one hundred parameters available for modification in the software, a selection of the most important ones is given in Table 3 .

After careful preparation of the process settings, the tool-paths for $3 \mathrm{D}$ printing and the G-code files were generated. Four build platforms were designed based on abovementioned settings. To avoid any failed parts, the lumbar implant prototype was manufactured in four print jobs (Figure 3), as follows: 1. one gliding ellipse, 2. two end plates; 3 . one sheath; 4 . one elastic annulus. In order to streamline the optimisation of the build platforms, several types of features are presented in the print preview, marked with different colours. Some of the different features are: travel, outer perimeter, inner perimeter, gap fill, solid layers, infill, bridge, support, dense support, raft, brim, prime pillar, and ooze shield (Figure 3). 
Table 3. Process parameters settings in Simplify 3D for the intervertebral disk implant prototype print jobs.

\begin{tabular}{|c|c|c|c|c|}
\hline $\begin{array}{l}\text { Nr. } \\
\text { Crt. }\end{array}$ & \multicolumn{2}{|r|}{ Parameter } & Units & Values \\
\hline 1 & \multirow{2}{*}{ Retraction } & Retraction distance & {$[\mathrm{mm}]$} & 1 \\
\hline 2 & & Retraction speed & {$[\mathrm{mm} / \mathrm{s}]$} & 40 \\
\hline 3 & \multirow{2}{*}{ Temperature } & $\begin{array}{l}\text { Primary Extruder (start printing/ } \\
\text { during printing) }\end{array}$ & {$\left[{ }^{0} \mathrm{C}\right]$} & $215 / 205$ \\
\hline 4 & & $\begin{array}{l}\text { Platform temperature (start printing/ } \\
\text { during printing) }\end{array}$ & {$\left[{ }^{0} \mathrm{C}\right]$} & $60 / 0$ \\
\hline 5 & Movement behaviour & Maximum allowed detour factor & - & 1 \\
\hline 6 & \multirow{3}{*}{ Speeds } & Default Printing speed & {$[\mathrm{mm} / \mathrm{s}]$} & 60 \\
\hline 7 & & $\mathrm{X} / \mathrm{Y}$ Axis movement speed & {$[\mathrm{mm} / \mathrm{s}]$} & 80 \\
\hline 8 & & Solid Infill underspeed & {$[\%]$} & 80 \\
\hline 9 & Wipe & Wipe distance & {$[\mathrm{mm}]$} & 2 \\
\hline 10 & Layer settings & Primary layer height & {$[\mathrm{mm}]$} & 0.15 \\
\hline 11 & \multirow{2}{*}{ Infill } & Interior fill percentage & {$[\%]$} & 50 \\
\hline 12 & & Minimum infill length & {$[\mathrm{mm}]$} & 2 \\
\hline 13 & Primary extrude toolhead & Extrusion multiplier & - & 1 \\
\hline 14 & \multirow{3}{*}{$\begin{array}{l}\text { Support material } \\
\text { generation }\end{array}$} & Support infill percentage & {$[\%]$} & 30 \\
\hline 15 & & Dense infill percentage & {$[\%]$} & 70 \\
\hline 16 & & Extra inflation distance & {$[\mathrm{mm}]$} & 1.4 \\
\hline
\end{tabular}

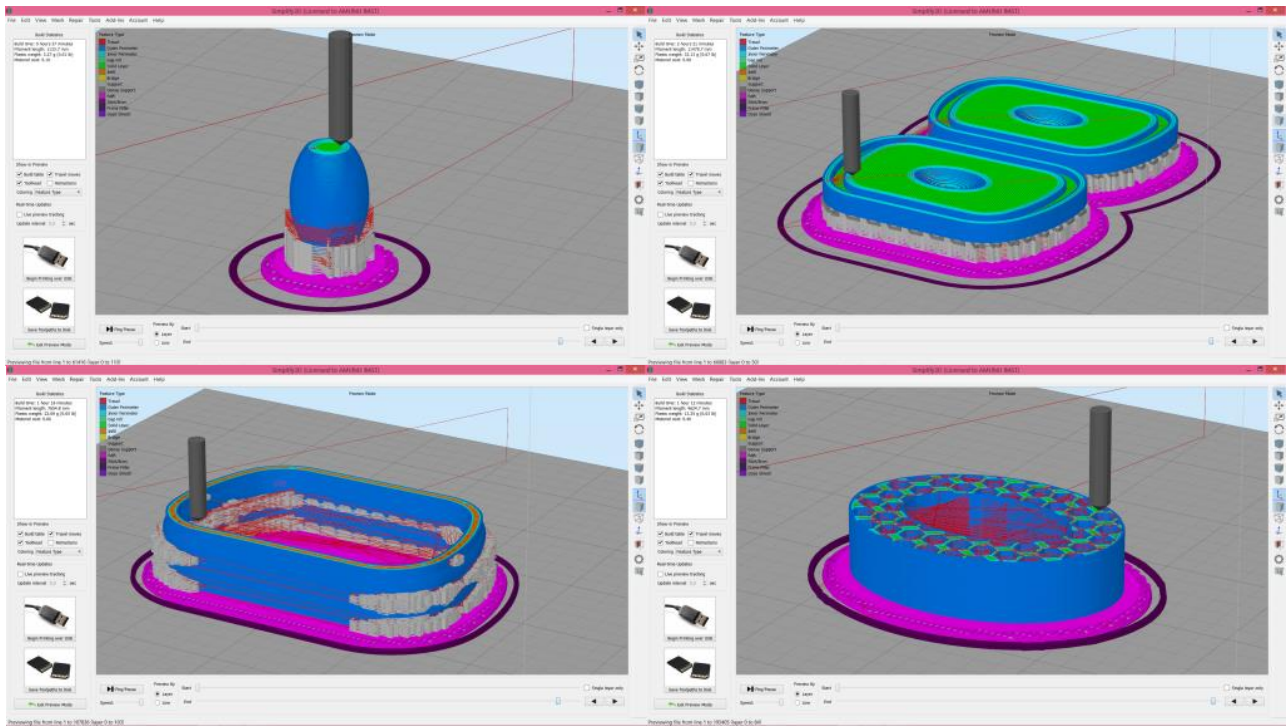

Fig. 3. Build platforms for the intervertebral disk implant prototype designed using Simplify 3D.

Build characteristics for the intervertebral disk implant prototype components are summarised in Table 4.

Table 4. Build characteristics for the intervertebral disk implant prototype components.

\begin{tabular}{|l|c|c|c|c|}
\hline & GLIDING ELLIPSE & ENDPLATES & SHEATH & $\begin{array}{c}\text { ELASTIC } \\
\text { ANNULUS }\end{array}$ \\
\hline Build time [hours:min] & $0: 29$ & $2: 21$ & $0: 45$ & $1: 12$ \\
\hline Filament length [mm] & 1263.3 & 11479.7 & 4736.5 & 4624.7 \\
\hline Plastic weight [g ] & 3.65 & 33.13 & 13.67 & 13.35 \\
\hline Material cost [units] & 0.11 & 0.99 & 0.41 & 0.40 \\
\hline
\end{tabular}


All five parts were successfully printed and post-processed (Figure 4). Postprocessing of the parts included support structure removal and deburring of any stranded filaments. The process lasted approximately ten minutes for all four print jobs. The lumbar intervertebral disk implant prototype components fitted together without any additional post-processing steps, thus the conception process of CAD models was validated. Furthermore, in order to validate the working principle and the surgical technique, evaluation of the prototype was undertaken by one neurosurgeon and one orthopaedic surgeon. Positive feedback from surgeons included remarks regarding the ease of implantation in terms of the surgical instruments used in the theatre. The design of the implant requires no additional tools, standard available surgical instruments being used for conducting the surgical procedure. Its' minimalistic and modular design makes it appropriate for implantation through two available surgical approaches, namely: anterior using an incision on the abdomen wall and a transperitoneal access; anterolateral using an abdominal retroperitoneal access and an extended posterior approach [14]. Some improvements to the designed concepts were suggested: additional fixation is needed, so the contact surface of the endplates should be equipped with more gripping elements; if custom manufacturing is available, the contact surfaces of the endplates should follow the anatomical profile of the patients' corresponding vertebral bodies; for extra support, the elastic annulus shape should follow the sheath shape, by an offset of 2-3 mm; further research should be undertaken to establish the optimum geometry of the elastic annulus and how different mesh structures influence the range of motion offered by the intervertebral disk implant.

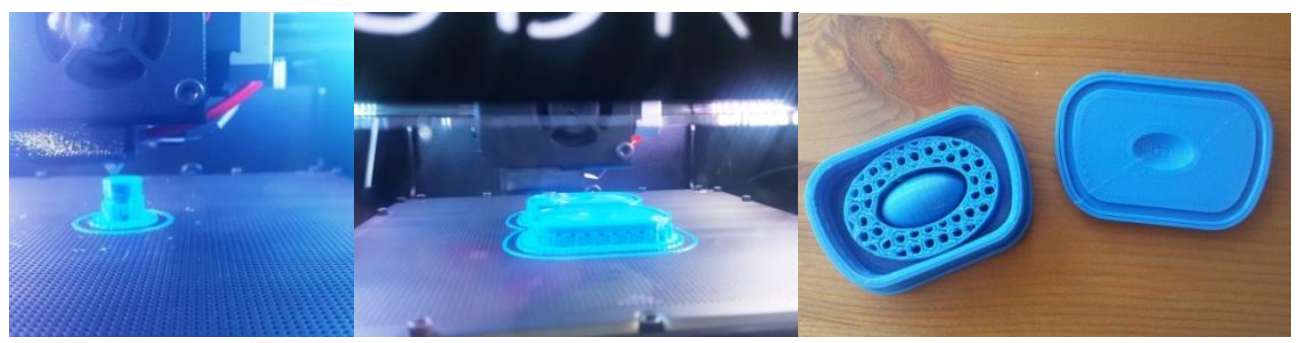

Fig. 4. 3D printing using FDM from PLA and first lumbar intervertebral disk implant prototype.

\section{Results interpretation}

Simulation results were analysed considering the following stages: Mesh compilation; Study simulation with integrated solver; First evaluation of simulation results; Optimise chart characteristics; Generation of the simulation reports; Interpretation of results; Simulation conclusions regarding the lumbar intervertebral disk implant concept model. Mesh was compiled with the characteristics presented in Table 1 and no errors were given by the mesh solver. Several studies were undertaken for each of the three defined hypotheses, as follows: Von Misses stress; URES: Resultant Displacement; ESTRN: Equivalent Strain. Simulations were run after mesh compilation and a first evaluation of the results led to the optimisation of chart plots characteristics. The deformation scale was adjusted from automatic to 500 units for all plots and no superimposed model was used. Value units were changed from N/m2 to $\mathrm{MPa}$ and a floating number format was set. Simulation results for Concept 1 are summarised in Table 5. Similar simulations were undertaken for concepts 2 and 3. Simulation results for all three concepts are summarized in Table 6. 
Table 5. Concept 1 load distribution simulation analysis.

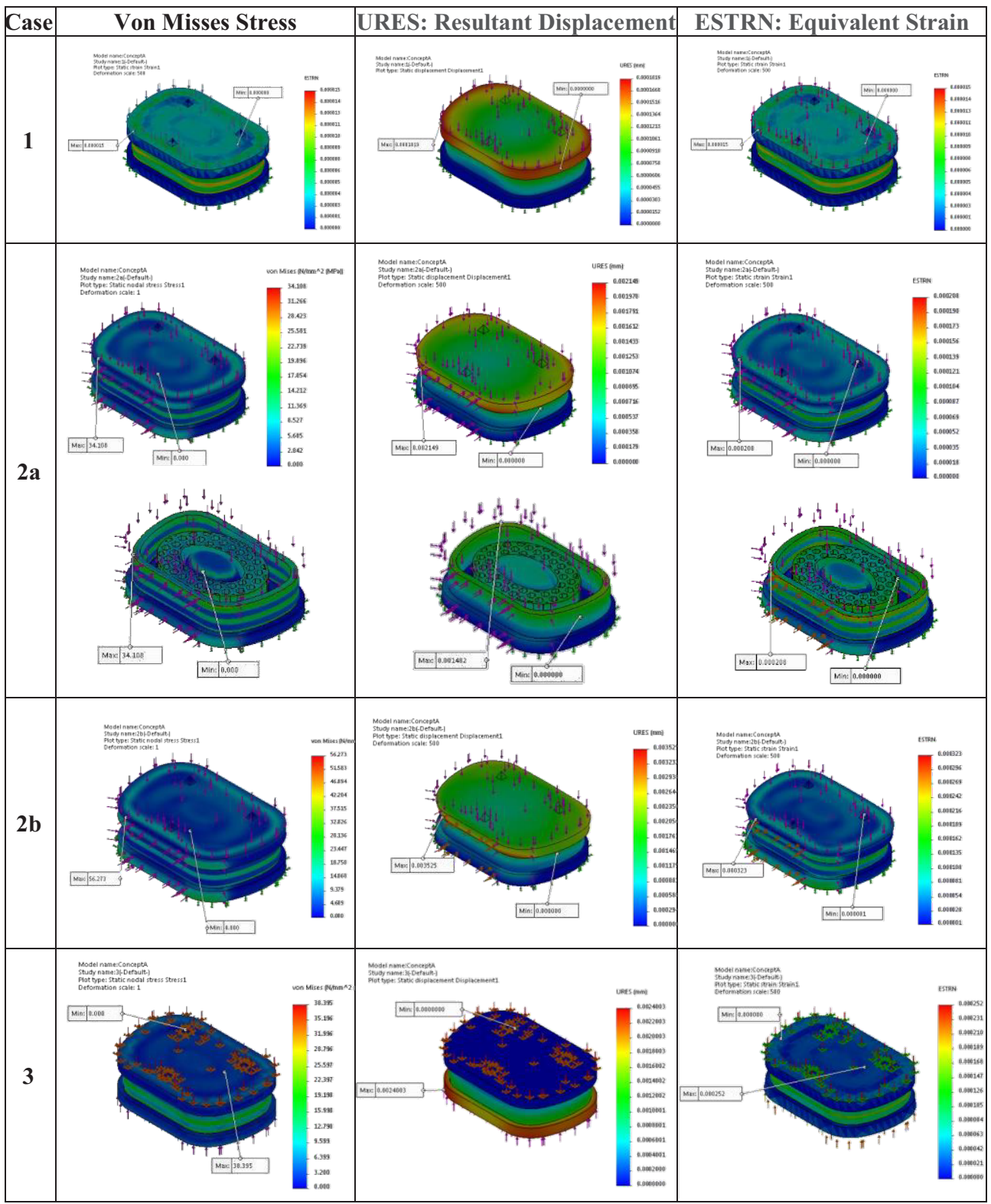

The von Misses Stress (Table 6) distribution obtained by FEA states weather the assembly will withstand the design load. All simulation maximum values were registered on the endplates components, thus the material characteristics of titanium alloy were taken into consideration for verification. Von Misses stress simulation results should be situated below the yield point value of Ti-6Al-4V which is $827.3708 \mathrm{MPa}$. As it can be seen in Table 6 concept 1 and concept 2 have Von Misses Stress values under the yield point of the used titanium alloy, thus the concepts will withstand the design load. Concept 3 does not withstand the design load for hypothesis $2 a, 2 b$ and 3 , with the following maximum obtained values: for hypothesis $2 a$ a maximum value of $1235.884 \mathrm{MPa}$ was obtained in mesh node 27045; for hypothesis $2 b$ a maximum value of $1629.21 \mathrm{MPa}$ was obtained in 
mesh node 27045; for hypothesis 2a a maximum value of $16111.806 \mathrm{MPa}$ was obtained in mesh node 284.

Table 6. Simulation results comparison for three lumbar intervertebral disk implant concepts: Von Misses Stress, URES and ESTRN.

\begin{tabular}{|c|c|c|c|c|}
\hline CONCEPTS & & CONCEPT 1 & CONCEPT 2 & CONCEPT 3 \\
\hline \multicolumn{5}{|c|}{ Hypothesis 1 - Normal up-right position } \\
\hline \multirow{2}{*}{$\begin{array}{c}\text { Von Misses Stress } \\
{[\mathrm{MPa}]}\end{array}$} & Min & $3.32 \cdot 10^{9}$ & 0.037 & $4.81 \cdot 10^{3}$ \\
\hline & Max & 2.484 & 34.891 & 127.256 \\
\hline \multirow{2}{*}{ URES $[\mathrm{mm}]$} & Min & 0 & 0 & 0 \\
\hline & Max & $1.83 \cdot 10^{4}$ & $4.11 \cdot 10^{4}$ & 0.025 \\
\hline \multirow{2}{*}{ ESTRN } & Min & $1.81 \cdot 10^{8}$ & $2.06 \cdot 10^{7}$ & $8.77 \cdot 10^{8}$ \\
\hline & Max & $1.52 \cdot 10^{5}$ & $4.18 \cdot 10^{5}$ & $6.93 \cdot 10^{4}$ \\
\hline \multicolumn{5}{|c|}{ Hypothesis 2a - Weight lifting at $\alpha=80^{0}$} \\
\hline \multirow{2}{*}{$\begin{array}{c}\text { Von Misses Stress } \\
{[\mathrm{MPa}]}\end{array}$} & Min & $7.54 \cdot 10^{8}$ & 0.478 & 0.044 \\
\hline & Max & 34.108 & 344.757 & 1235.884 \\
\hline \multirow{2}{*}{ URES $[\mathrm{mm}]$} & Min & 0 & 0 & 0 \\
\hline & Max & $2.15 \cdot 10^{3}$ & $4.012 \cdot 10^{3}$ & 0.226 \\
\hline \multirow{2}{*}{ ESTRN } & Min & $4.27 \cdot 10^{7}$ & $1.93 \cdot 10^{6}$ & $1.32 \cdot 10^{6}$ \\
\hline & Max & $2.08 \cdot 10^{4}$ & $4.10 \cdot 10^{4}$ & $6.73 \cdot 10^{3}$ \\
\hline \multicolumn{5}{|c|}{ Hypothesis $2 \mathrm{~b}-$ Weight lifting at $\alpha=\mathbf{6 5}^{\circ}$} \\
\hline \multirow{2}{*}{$\begin{array}{c}\text { Von Misses Stress } \\
{[\mathrm{MPa}]}\end{array}$} & Min & $1.15 \cdot 10^{7}$ & 0.520 & 0.056 \\
\hline & Max & 56.273 & 388.241 & 1629.21 \\
\hline \multirow{2}{*}{ URES [mm] } & Min & 0 & 0 & 0 \\
\hline & Max & $3.525 \cdot 10^{3}$ & $5.330 \cdot 10^{3}$ & 0.2899 \\
\hline \multirow{2}{*}{ ESTRN } & Min & $7.44 \cdot 10^{7}$ & $4.01 \cdot 10^{6}$ & $1.69 \cdot 10^{6}$ \\
\hline & Max & $3.23 \cdot 10^{4}$ & $5.19 \cdot 10^{4}$ & $8.87 \cdot 10^{3}$ \\
\hline \multicolumn{5}{|c|}{ Hypothesis 3 - Shock in the lumbar region } \\
\hline \multirow{2}{*}{$\begin{array}{c}\text { Von Misses Stress } \\
{[\mathrm{MPa}]}\end{array}$} & Min & $6.009 \cdot 10^{7}$ & 0.757 & 0.307 \\
\hline & Max & 38.395 & 316.117 & 16111.806 \\
\hline \multirow{2}{*}{ URES [mm] } & Min & 0 & 0 & 0 \\
\hline & Max & $2.41 \cdot 10^{3}$ & $6.06 \cdot 10^{3}$ & 0.435 \\
\hline \multirow{2}{*}{ ESTRN } & Min & $2.63 \cdot 10^{7}$ & $5.06 \cdot 10^{6}$ & $4.22 \cdot 10^{6}$ \\
\hline & $\operatorname{Max}$ & $2.52 \cdot 10^{4}$ & $5.83 \cdot 10^{4}$ & 0.0261 \\
\hline
\end{tabular}

URES study is used to determine how the CAD model moves under the defined loads. The Resultant Displacement (Table 6) generates the magnitude of the resultant (compounded from the $\mathrm{X}, \mathrm{Y}$ and $\mathrm{Z}$ directions) reaction force. According to standard ISO 18192-1:2011 [23] the maximum deflection value for a spinal artificial disk is $\pm 1.5 \mathrm{~mm}$ displacement. According to simulation results presented in Table 6, all concept values fall within the deflection limits of the abovementioned standard. The highest displacement values are recorded for Concept 3, simulated in hypothesis 3, namely a maximum displacement computed value of $0.435 \mathrm{~mm}$ in mesh node 9164 .

The equivalent strain was used to measure the geometric response and the change in shape (deformation) due to applied forces for the three defined load scenarios. ESTRN: equivalent strain is computed as the rapport between the maximum triaxial stress and the Elastic Modulus. In order for the assembly to withstand the design load, ESTRN values (Table 6) should be less than the coefficient given by the ratio between the Yield Strength and the Elastic Modulus. Ti-6Al-4V has an Elastic Modulus of $104800.31 \mathrm{MPa}$, thus all simulation results values were compared with a 0.0079 coefficient. Concept 1 and Concept 2 both have ESTRN values situated under 0.0079, thus withstanding the design load. 
According to the obtained results, concept 3 withstands the design load only for hypotheses 1 and $2 a$. For hypothesis $2 b$ and 3 simulated values exceed the calculated coefficient, leading to design load failure. In case of hypothesis $2 b$ failure was due to an $8.87 \cdot 10^{3}$ ESTRN value generated in mesh node 13759 . For hypothesis 3 , strain failure occurred due to a 0.0261 ESTRN value in mesh node 13346 .

Based on simulation results, with the lowest stress, strain and displacement values, Concept 1 was selected for further research and development.

\section{Conclusions}

The research paper proposed a design process of a new lumbar intervertebral disk implant, which replicates the functions of a natural intervertebral disk, by limiting the anatomical movements of the trunk. Three main stages were used in the development of the new concept model: CAD modelling, FEA simulations and rapid prototyping. FEA simulations were undertaken for three concepts, using three study types: Von Misses Stress; URES: Resultant Displacement; ESTRN: Equivalent Strain. IVD Concepts 1 and 2 obtained simulation values which fell within imposed limits. Concept 3 failed design loads for two hypotheses, being eliminated from concept selection. Rapid prototyping was done for concept validation and component fitting using a 3D Kreator equipment with $1.75 \mathrm{~mm}$ standard PLA filament. Further research and development will be undertaken on Concept 1, which showed the optimum simulation results.

Future research includes four main stages, based on surgeons feedback: position and fit validation of the implant with custom patient anatomical data; 3D printing of an intermediary prototype with flexible components to validate the prescribed anatomical motions of the trunk, namely lateral flexion $\left(0^{\circ} / 40^{\circ}\right)$, flexion $\left(0^{\circ} / 100^{\circ}\right)$, extension $\left(0^{\circ} / 50^{\circ}\right)$ and torsion $\left(0^{\circ} / 40^{\circ}\right)$; manufacturing of material samples for in vitro and in vivo testing; develop an implantation protocol. Validation with DICOM patient data will be fairly easy as parametric $\mathrm{CAD}$ models were used in the development process of the intervertebral disk implant. For validation of the prescribed trunk motions, a model of the lumbar spine will be $3 \mathrm{D}$ printed for assembly and fitting with the implant prototype. An intermediary prototype will be 3D printed with Form 2 equipment using tough resin (TOTL04) for the endplates and gliding ellipse, and flexible resin (FLGR02) for the elastic annulus and sheath. Material samples for in vivo and in vitro tests will be manufactured from titanium alloy using SLM technology and from silicone RTV medical rubber using an open cast process in custom cast mould. Implantation protocol will be developed in collaboration with medical doctors and other industry specialists.

This work has been funded by University Politehnica of Bucharest, through the "Excellence Research Grants" Program, UPB - GEX 2017. Identifier: UPB- GEX2017, ID No. 26 /2017 (BIOSHIELD)".

\section{References}

1. A. Officer, A.Posarac (Executive editors), World report on disability, World Health Organization, ISBN 978-92-4-068521-5 (2011)

2. C. Thompson, J. Mutch, S. Parent, J.M. Mac-Thiong, J Spinal Cord Med 38 (2), 214 223 (2015)

3. A. Singh, L. Tetreault, S. Kalsi-Ryan, A. Nouri, M.G. Fehlings, Clin Epidemiol 6, 309-331 (2014)

4. Spinal Implants and Surgical Devices Market - Global Forecast to 2021, Global Report, ID: 3978582 (2016) 
5. S.M. Kurtz, A.A. Edidin, Spine Technology Handbook, ISBN: 978-0-12-369390-7 (2006)

6. P.J. Slosar, J. Spinal Research Foundation 9 (1), 34-41 (2014)

7. L. Harvey, Management of Spinal Cord Injuries: A Guide for Physiotherapists, Elsevier Health Sciences, ISBN 0-443-06858-5 (2008)

8. M.N. Melkerson, J.S. Kirkpatrick, S.L. Griffith, ASTM International, West Conshohocken (2003)

9. M. Nordin, V.H. Frankel, Basic Biomechanics of the Musculoskeletal System, $4^{\text {th }}$ Edition, LWW Publisher, ISBN-13: 978-1609133351 (2012)

10. D.H. Kim, F.P. Cammisa, R.G. Fessler, Dynamic reconstruction of the spine, Thieme (2006)

11. C.J. Korge, F. Heider, H.M. Mayer, Oper Orthop Traumatol 9, 480-494 (2010)

12. R. Putz, J. Waschke, Sobotta Atlas of Human Anatomy, Vol. 1: General Anatomy and Musculoskeletal System, Editors Paulsen F. and Waschke J., $15^{\text {th }}$ Ed., Elsevier Urban \& Fischer, ISBN 978-0-7234 -3733-8 (2011)

13. R.C. Reis, M.F. de Oliveira, J.M. Rotta, R.V. Botelho, Open Orthop J 9, 20-25 (2015)

14. E.C. Benzel, Spine Surgery: Techniques, Complication Avoidance \& Management, $3^{\text {rd }}$ Edition, 1, Elsevier, Saunders, ISBN: 978-1-4377-0587-4 (2012)

15. T. Özel, P.J. Bártolo, E. Ceretti, J. De Ciurana Gay, C.A. Rodriguez, J.V.L. Da Silva, Biomedical Devices: Design, Prototyping, and Manufacturing, Wiley Publishing, ISBN: 978-1-118-47892-9 (2016)

16. M. Marcolongo, S. Sarkar, N. Ganesh, 6, 127-145 (2011)

17. T. Wholers, T. Caffrey, Wholers Report 2014 - 3D Printing and Additive Manufacturing State of the Industry, Wholers Associates (2014)

18. G.H. Snyder, M. Cotteleer, B. Kotek, 3D opportunity in medical technology: Additive manufacturing comes to life, A Deloitte series on additive manufacturing, Deloite University Press, US (2014)

19. N. de Beer, A.van der Merwe, Rapid Prototyping J 19 (2), 126-139 (2013)

20. V.N. Chougule, A.V. Mulay, B.B. Ahuja, Procedia Eng 97, 212-219 (2014)

21. A.S. Frîncu, Development of a production system project and process for a spinal implant, Graduate Project, M.E. Ulmeanu, C.V. Doicin (Coord.), Bucharest (2017)

22. C.V. Toen, M.M. Sran, S.N. Robinovitch, P.A. Cripton, Spine (Phila Pa 1976) 37 (9), E519-E527 (2012)

23. ISO 18192-1:2011, Test Implants for surgery - Wear of total intervertebral spinal disc prostheses - Part 1: Loading and displacement parameters for wear testing and corresponding environmental conditions for test, International Organisation for Standardization, Geneva, Switzerland (www.iso.org) 